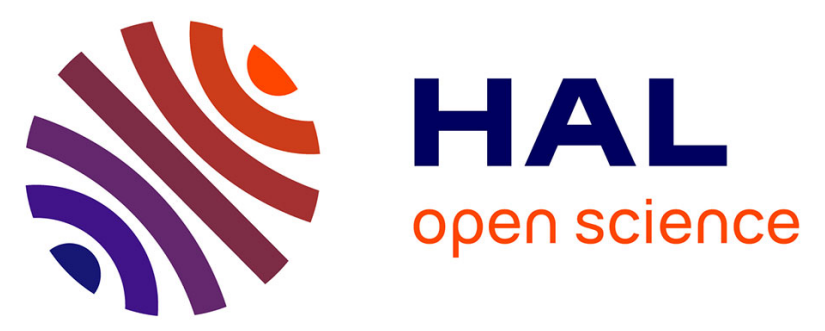

\title{
Laser demonstration with highly doped Yb:Gd2O3 and Yb:Y2O3 crystals grown by an original flux method
} Frédéric Druon, Matias Velázquez, Philippe Veber, Sylvie Janicot, Viraphong

Oudomsack, Gabriel Buse, Marwan Abdou Ahmed, Thomas Graf, Daniel Rytz, Patrick Georges

\section{To cite this version:}

Frédéric Druon, Matias Velázquez, Philippe Veber, Sylvie Janicot, Viraphong Oudomsack, et al.. Laser demonstration with highly doped $\mathrm{Yb}: \mathrm{Gd} 2 \mathrm{O} 3$ and $\mathrm{Yb}: \mathrm{Y} 2 \mathrm{O} 3$ crystals grown by an original flux method. Optics Letters, 2013, 38 (20), pp.4146-4149. 10.1364/OL.38.004146 . hal-00904497

\section{HAL Id: hal-00904497 \\ https://hal-iogs.archives-ouvertes.fr/hal-00904497}

Submitted on 22 Apr 2016

HAL is a multi-disciplinary open access archive for the deposit and dissemination of scientific research documents, whether they are published or not. The documents may come from teaching and research institutions in France or abroad, or from public or private research centers.
L'archive ouverte pluridisciplinaire HAL, est destinée au dépôt et à la diffusion de documents scientifiques de niveau recherche, publiés ou non, émanant des établissements d'enseignement et de recherche français ou étrangers, des laboratoires publics ou privés. 


\title{
Laser demonstration with highly doped $\mathrm{Yb}: \mathrm{Gd}_{2} \mathrm{O}_{3}$ and $\mathrm{Yb}: \mathrm{Y}_{2} \mathrm{O}_{3}$ crystals grown by an original flux method
}

\author{
Frédéric Druon,,${ }^{1, *}$ Matias Velázquez, ${ }^{2}$ Philippe Veber, ${ }^{2}$ Sylvie Janicot, ${ }^{1}$ Oudomsack Viraphong, ${ }^{2}$ Gabriel Buşe, ${ }^{2}$ \\ Marwan Abdou Ahmed, ${ }^{3}$ Thomas Graf, ${ }^{3}$ Daniel Rytz, ${ }^{4}$ and Patrick Georges ${ }^{1}$ \\ ${ }^{1}$ Laboratoire Charles Fabry, Institut d'Optique, CNRS, Université Paris Sud., 2, Avenue Augustin Fresnel, \\ 91127 Palaiseau, Cedex, France \\ ${ }^{2}$ Institut de Chimie de la Matière Condensée de Bordeaux, ICMCB-CNRS UPR 9048, Université de Bordeaux, 87, \\ Avenue du Docteur Albert Schweitzer, 33608 PESSAC, Cedex, France \\ ${ }^{3}$ Institut für Strahlwerkzeuge (IFSW), Universität Stuttgart, Pfaffenwaldring 43,70569 Stuttgart, Germany \\ ${ }^{4}$ Fee-GmbH, Struthstrasse 2, 55743 Idar-Oberstein, Germany \\ ${ }^{*}$ Corresponding author: frederic.druon@institutoptique.fr
}

\begin{abstract}
We present, to the best of our knowledge, the first laser demonstration of an Yb-doped $\mathrm{Gd}_{2} \mathrm{O}_{3}$ cubic crystal. This crystal was obtained by the flux method using an original borate-based solvent, which was particularly well suited to the growth of rare earth sesquioxide crystals at half the working temperature of classical growth techniques. This flux method is a very interesting alternative for the production of laser sesquioxide crystals, not only because it provides access to new matrices of the cubic polymorph, but also because it permits high $\mathrm{Yb}^{3+}$-doping levels for these crystals. The first laser results of two highly $\mathrm{Yb}^{3+}$-doped sesquioxides, namely $\mathrm{Gd}_{2} \mathrm{O}_{3}$ and $\mathrm{Y}_{2} \mathrm{O}_{3}$, grown by this flux method are presented here, including the Ti:sapphire and diode pumping configurations. Laser efficiencies and emission spectra for these two crystals were studied and compared.
\end{abstract}

Ytterbium-doped cubic rare earth sesquioxide $\left(\operatorname{Re}_{2} \mathrm{O}_{3}\right.$, where Re is typically $\mathrm{Lu}, \mathrm{Y}$, or Sc) crystals have raised an extremely intense interest in the development of high-power diode-pumped solid-state lasers [1-5]. In fact, very high power was demonstrated in $\mathrm{cw}$ [ $[\underline{6}, \underline{7}]$ and mode-locked operations with femtosecond $[8,9]$ pulses, especially when using thin-disk technology. In 2010, a successful power scaling of a passively mode-locked femtosecond thin-disk laser was achieved with $\mathrm{Yb}: \mathrm{Lu}_{2} \mathrm{O}_{3}$ crystals, which delivered an average power of $141 \mathrm{~W}$ [9]. In 2011, an output power of $670 \mathrm{~W}$ was obtained in a cw regime also by use of the thin-disk concept [7]. On the other hand, ultrashort-pulse oscillators using bulk crystals have been demonstrated with the generation of pulses in the range of $60 \mathrm{fs}[\underline{10}]$. The $\mathrm{Yb}$-doped sesquioxide crystals are attractive because they combine high emission gains, good thermomechanical properties, and substantial emission bandwidths (at least superior to that of Yb:YAG). This makes them very interesting and very competitive to Yb:YAG for high-power laser development, especially within thin-disk or slab technology. Nevertheless, examining the large amount of publications concerning these crystals leads one to an unquestionable statement: the key issue for laser development with these materials remains their growth process [4]. Accessing reproducibly good quality crystals for effective laser performance remains challenging because of their high melting temperature and, in some cases like $\mathrm{Gd}_{2} \mathrm{O}_{3}$, because of their rich polymorphism. Moreover, in our point of view, the somewhat counter intuitive and unexpected results arising from our growth of these crystals is the high $\mathrm{Yb}^{3+}$-doping content achieved in $\mathrm{Gd}_{2} \mathrm{O}_{3}$ and $\mathrm{Y}_{2} \mathrm{O}_{3}$ single crystals of the cubic phase. The first laser demonstrations with these crystals are presented here and the results are analyzed in the accompanying text and illustrations.

Several methods have been put forward these last three years to grow pure and $\mathrm{RE}^{3+}$-doped $\left(\mathrm{RE}^{\prime}=\mathrm{Tm}\right.$, $\mathrm{Er}$, or $\mathrm{Yb})$ cubic $\mathrm{RE}_{2} \mathrm{O}_{3}(\mathrm{RE}=\mathrm{Y}, \mathrm{Lu}$, or $\mathrm{Sc})$ single crystals [11-14]. The main current drawback of the classical methods is that they do not circumvent the high melting point of these compounds $\left(\sim 2400^{\circ} \mathrm{C}-2500^{\circ} \mathrm{C}\right)$, and for some of them, a series of structural phase transitions occur upon cooling. The high melting temperature makes the classical growth methods [e.g., Czochralski, Bridgman, heat exchanger method (HEM)] quite challenging, potentially explosive, and expensive. This is due to the use of specific rhenium crucibles that require a highly reduced atmosphere by means of a high-temperature $\mathrm{H}_{2}$-based gas flow, which favors $\mathrm{Yb}^{2+}$ formation and Re volatilization. The reproducible access to $\mathrm{Yb}^{3+}$-doped cubic $\mathrm{Re}_{2} \mathrm{O}_{3}$ for laser applications has thus been hindered until now by these constraints. An alternative flux method has been recently proposed that uses a heavy metal free solvent [14]. The method allows operations at half the melting point temperature in air so it does not require any annealing process to reoxidize $\mathrm{Yb}^{2+}$ cations. Moreover, it permits the growth of original crystals, such as cubic (and not monoclinic) $\mathrm{Gd}_{2} \mathrm{O}_{3}$ crystals, as well as achieves high $\mathrm{Yb}^{3+}$ doping levels in these materials with virtually no formation of Yb-pairs at least up to $6 \%$ rare earth substitution rates; whereas, $\mathrm{Lu}_{2} \mathrm{O}_{3}$ and $\mathrm{Sc}_{2} \mathrm{O}_{3}$ directly melt from the cubic solid phase to the liquid one. $\mathrm{Y}_{2} \mathrm{O}_{3}$ at $2327^{\circ} \mathrm{C}$ first transforms into a hightemperature hexagonal form before melting, and $\mathrm{Gd}_{2} \mathrm{O}_{3}$ undergoes no less than three phase transitions 
upon heating. According to the literature, the cubic-tomonoclinic phase transition in $\mathrm{Gd}_{2} \mathrm{O}_{3}$ occurs at 1200 , 1273 , or $1288^{\circ} \mathrm{C}$ [15-17] with first-order characteristics, that is, $\Delta \mathrm{H}_{t} \approx 4.7$ [16], 5.3 [17], or $5.7 \mathrm{~kJ} / \mathrm{mol}$. [18] and a substantial relative volume decrease of about $-10 \%$, which unavoidably entails crystals of poor quality, if not completely cracked [19]. One of the very interesting thermodynamical properties exhibited by the solvent $\mathrm{Li}_{6} \mathrm{RE}\left(\mathrm{BO}_{3}\right)_{3}$ that we use is that it probably dissolves much more $\mathrm{Gd}_{2} \mathrm{O}_{3}$ than $\mathrm{Yb}_{2} \mathrm{O}_{3}$, which leads to high substitution rates. For example, we were capable of achieving a doping level as high as $14 \%$ in $\mathrm{Gd}_{2} \mathrm{O}_{3}$ (which leads to an average composition of $\mathrm{Gd}_{1.72} \mathrm{Yb}_{0.28} \mathrm{O}_{3}$, that is, an $\mathrm{Yb}^{3+}$ concentration of $3.6 \times 10^{21} \mathrm{~cm}^{-3}$ ), starting from a $6.75 \% \mathrm{Yb}$-doped molten bath, and $6.5 \%$ in $\mathrm{Y}_{2} \mathrm{O}_{3}$ (leading to $\mathrm{Y}_{1.87} \mathrm{Yb}_{0.13} \mathrm{O}_{3}$, that is, an $\mathrm{Yb}^{3+}$ concentration of $\left.1.74 \times 10^{21} \mathrm{~cm}^{-3}\right)$, starting from a $4.15 \% \mathrm{Yb}$-doped molten bath. Such a concentration proves to be much more off the experimental lifetime optimum resulting from the antagonistic effects of self-trapping and concentration quenching. The high doping level is one important issue for the thin-disk laser architecture in which the absorption is reduced. Indeed, it permits a reduction in thickness of the crystals down to a few hundred microns or under, which then allows for efficient cooling while maintaining a high absorption yield under this thin-disk laser operation. Nevertheless, materials grown by this new flux method have never been demonstrated in laser operations before. Therefore, we built a simple laser setup to evaluate these crystals in standard bulk configuration.

The experiment was performed with $1 \mathrm{~mm}$ long crystals. The crystals were not coated and were positioned to couple back the Fresnel reflexions in the cavity. Several cavities were set up. The V-shape cavities integrated 3 mirrors: a dichroic plane mirror, a convex mirror with a ROC of $50 \mathrm{~mm}$, and a plane output coupler with 4 , 6, or 10\% (Figs. 1 and 3). Both Ti:sapphire (Ti:Sa) and diode pumping were demonstrated in $\mathrm{cw}$ and quasi-cw (duty cycle of 0.17 at $40 \mathrm{~Hz}$ ) operations. The Ti:Sa laser delivered up to $3 \mathrm{~W}$ of output power with a wavelength around $977 \mathrm{~nm}$. The fiber-coupled pumping laser diode used in the additional experiment emitted up to $6.5 \mathrm{~W}$

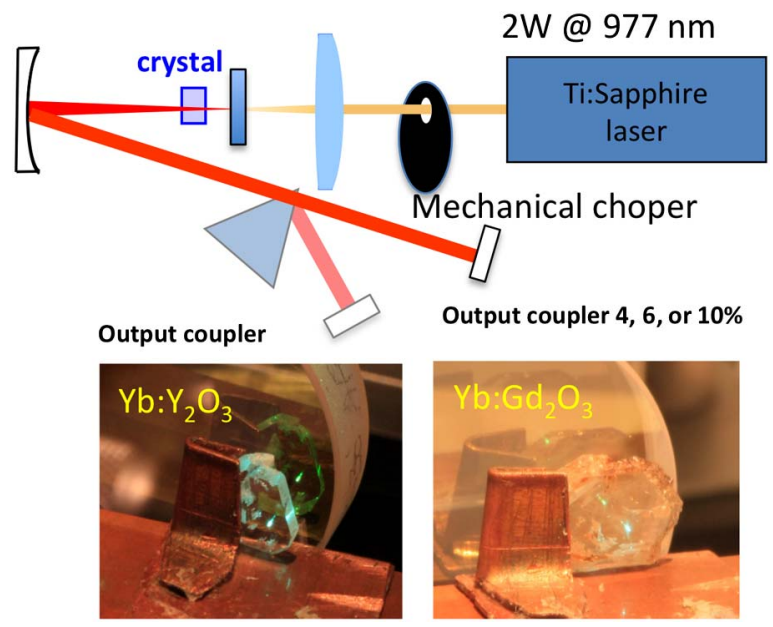

Fig. 1. (Top) Cavity setup for the Ti:Sa pumping and tunability experiment. (Bottom) Pictures of crystals and their holders.

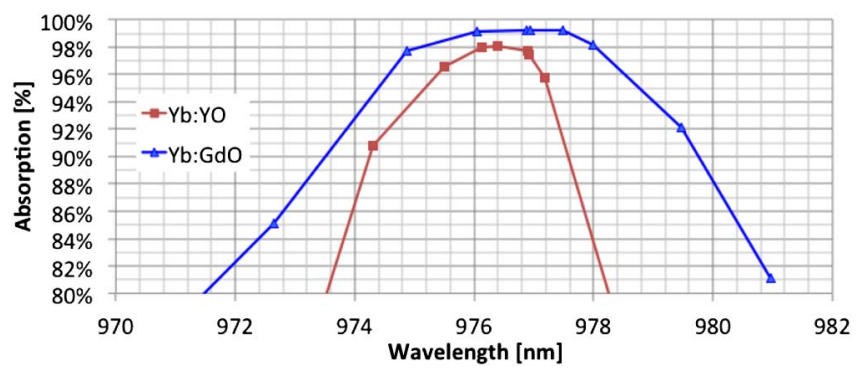

Fig. 2. Absorption for $1 \mathrm{~mm}$ long $14 \% \mathrm{Yb}$-doped $\mathrm{Gd}_{2} \mathrm{O}_{3}$ and $6.5 \% \mathrm{Yb}$-doped $\mathrm{Y}_{2} \mathrm{O}_{3}$ crystals.

power out of a $50 \mu \mathrm{m}$ core-diameter fiber with a NA of 0.22 . Since the crystal shape does not allow for heat extraction (see Fig. 1), and due to the strong absorption, the cw operation was limited to only few watts of pump power. The pump absorption wavelength was finely tuned using the Ti:Sa laser and the optimum for both crystals occurred between 976 and $977 \mathrm{~nm}$ (Fig. 2) with an absorption around 98\%-99\% (corrected from the Fresnel losses). The pump beam diameter both for Ti:Sa and fiber-coupled diode pumping was $60 \mu \mathrm{m}$ and it matched the laser beam.

The optimal output coupling was $4 \%$ for the $\mathrm{Yb}: \mathrm{Gd}_{2} \mathrm{O}_{3}$ and $6 \%$ for the $\mathrm{Yb}: \mathrm{Y}_{2} \mathrm{O}_{3}$. In the quasi-cw operation, the slope efficiency with Ti:Sa pumping was measured to be $45 \%$ for $\mathrm{Yb}: \mathrm{Gd}_{2} \mathrm{O}_{3}$ with the threshold at $464 \mathrm{~mW}$ of absorbed pump power (peak power) and $66 \%$ for $\mathrm{Yb}: \mathrm{Y}_{2} \mathrm{O}_{3}$ with the threshold at $212 \mathrm{~mW}$. One can find better efficiencies exceeding $70 \%$ that were obtained with other isotypes, such as $\mathrm{Yb}: \mathrm{Lu}_{2} \mathrm{O}_{3}$ and $\mathrm{Yb}_{2} \mathrm{Sc}_{2} \mathrm{O}_{3}[6,7,20,21]$. In fact, due to the high absorption of the crystals, the reabsorption limits the laser efficiency that can be obtained, which demonstrates the good quality of the $\mathrm{Yb}: \mathrm{Y}_{2} \mathrm{O}_{3}$ sample tested.

This difference in performance between the two crystals also occurred with diode pumping; as shown in Fig. 3 , the threshold for $\mathrm{Yb}: \mathrm{Gd}_{2} \mathrm{O}_{3}$ and $\mathrm{Yb}: \mathrm{Y}_{2} \mathrm{O}_{3}$ increased to $729 \mathrm{~mW}$ (absorbed power) and $307 \mathrm{~mW}$, respectively.
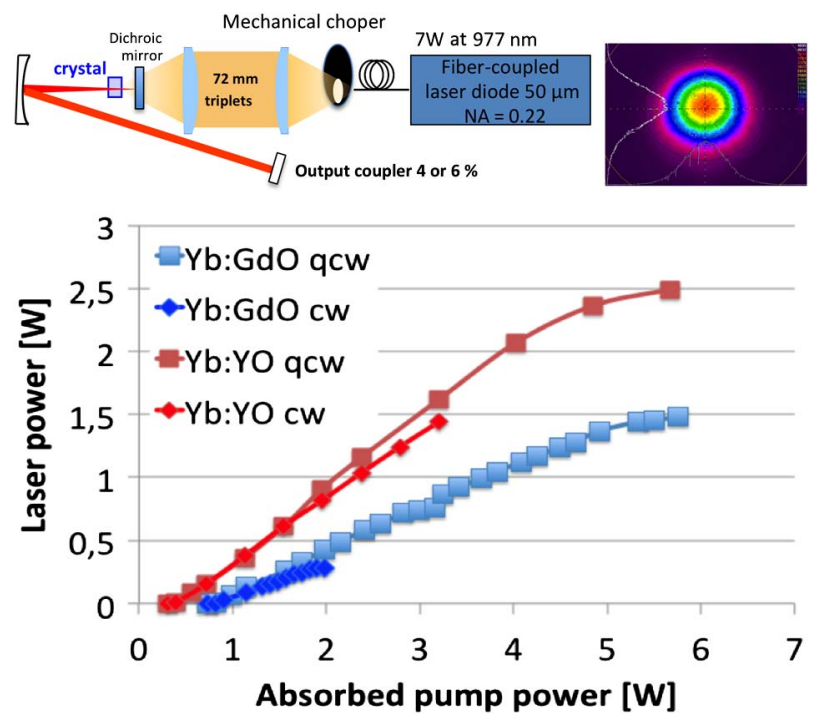

Fig. 3. (Top) Experimental setup of the diode-pumped cavity and associated laser beam profile. (Bottom) Laser powers for $\mathrm{Yb}: \mathrm{Gd}_{2} \mathrm{O}_{3}$ and $\mathrm{Yb}: \mathrm{Y}_{2} \mathrm{O}_{3}$ versus diode pump power. 


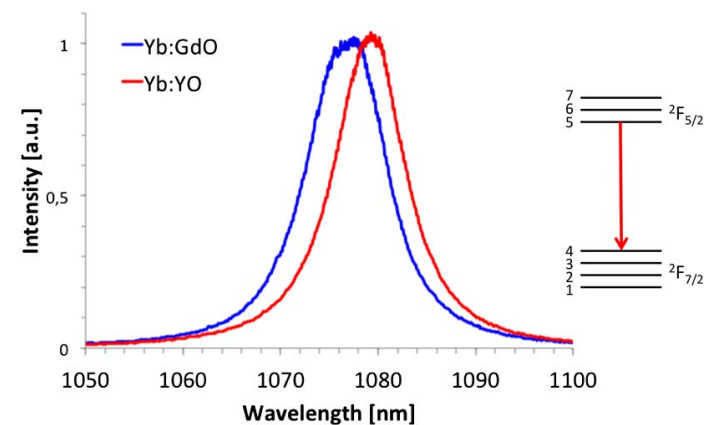

Fig. 4. Laser emission spectra for highly doped $\mathrm{Yb}: \mathrm{Gd}_{2} \mathrm{O}_{3}$ and $\mathrm{Yb}: \mathrm{Y}_{2} \mathrm{O}_{3}$.

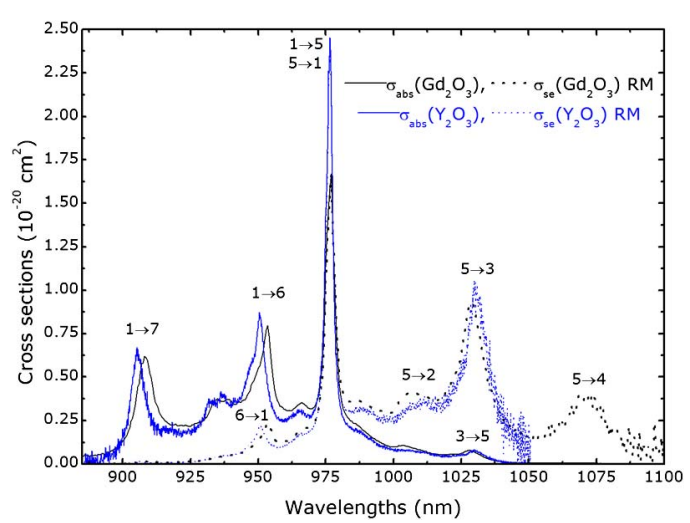

Fig. 5. Emission and absorption cross sections for $\mathrm{Yb}: \mathrm{Gd}_{2} \mathrm{O}_{3}$ and $\mathrm{Yb}: \mathrm{Y}_{2} \mathrm{O}_{3}$.

The slope efficiencies also dropped to $33 \%$ for $\mathrm{Yb}: \mathrm{Gd}_{2} \mathrm{O}_{3}$ and $58 \%$ for $\mathrm{Yb}: \mathrm{Y}_{2} \mathrm{O}_{3}$. In the cw operation with diode pumping, the slope efficiency was further reduced down to $26 \%$ for $\mathrm{Yb}: \mathrm{Gd}_{2} \mathrm{O}_{3}$ and $51 \%$ for $\mathrm{Yb}_{2} \mathrm{Y}_{2} \mathrm{O}_{3}$ because of thermal issues. In order to avoid any deteriorations of the crystals, the maximum cw pump power was deliberately limited to $1.9 \mathrm{~W}$ for $\mathrm{Yb}: \mathrm{Gd}_{2} \mathrm{O}_{3}$, which allowed us to obtain $285 \mathrm{~mW}$ of output power. For the $\mathrm{Yb}: \mathrm{Y}_{2} \mathrm{O}_{3}$ sample, the maximum laser power was $1.4 \mathrm{~W}$ for a maximum pump power of $3.2 \mathrm{~W}$.

The emission spectra were measured in a quasi-cw regime using a $0.2 \mathrm{~nm}$ resolution spectrometer (Fig. 4) with an integration time of $100 \mathrm{~ms}$ (integrating the spectrum over all the quasi-cw pulse). The high-doping signature clearly appeared with evidence of strong reabsorption. In fact, the natural wavelength emission occurred between the lower ${ }^{2} \mathrm{~F}_{5 / 2}$ and the upper ${ }^{2} \mathrm{~F}_{7 / 2}$ lines (5-4 lines in Figs. 4 and 5) of the $\mathrm{Yb}^{3+}$ cations, which corresponds to $1076 . \overline{\mathrm{nm}}$ for $\mathrm{Yb}: \mathrm{Gd}_{2} \mathrm{O}_{3}$ and $1078.6 \mathrm{~nm}$ for $\mathrm{Yb}: \mathrm{Y}_{2} \mathrm{O}_{3}$ (Fig. 4).

The wavelength tunability was evaluated by inserting a prism in the cavity (see Fig. 1). The $1040 \mathrm{~nm}$ band (5-3 line in Fig. 4) was only accessible with $\mathrm{Yb}_{2} \mathrm{Y}_{2} \mathrm{O}_{3}$ because of the better crystal quality and a lower doping concentration. One noticeable point in Fig. $\underline{6}$ is that the shape of the 5-4 transition is less sharp and broader in the case of $\mathrm{Yb}: \mathrm{Gd}_{2} \mathrm{O}_{3}$ than in the case of $\mathrm{Yb}: \mathrm{Y}_{2} \mathrm{O}_{3}$, where the emission was distributed from 1069 to $1083 \mathrm{~nm}$ for $\mathrm{Yb}: \mathrm{Gd}_{2} \mathrm{O}_{3}$ and from 1069 to $1081 \mathrm{~nm}$ for $\mathrm{Yb}: \mathrm{Y}_{2} \mathrm{O}_{3}$.

To conclude, we demonstrated laser operations with sesquioxide single crystals grown by an innovative flux technique. This technique has been validated with

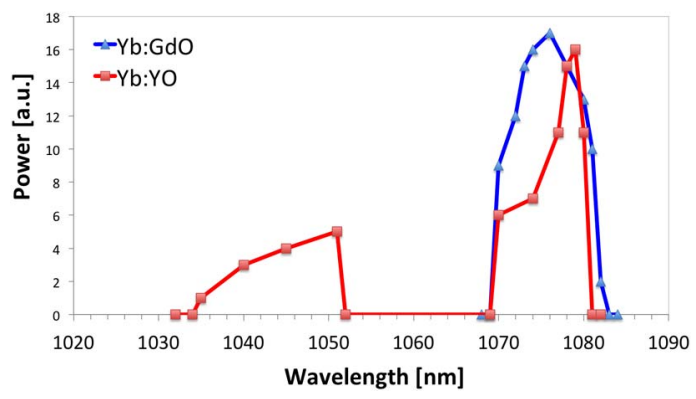

Fig. 6. Laser tunability for $\mathrm{Yb}: \mathrm{Gd}_{2} \mathrm{O}_{3}$ and $\mathrm{Yb}: \mathrm{Y}_{2} \mathrm{O}_{3}$.

$\mathrm{Yb}: \mathrm{Y}_{2} \mathrm{O}_{3}$, whose laser efficiency was in the range of $60 \%$ with an emission of $1.4 \mathrm{~W}$ for $3.2 \mathrm{~W}$ of pump power, which turns out to compare favorably with the crystals obtained by means of other growth techniques. Additionally, this technique not only strongly reduces the risks and the costs of the growing process for sesquioxide crystals compared to other classical growth methods, but it also leads to the crystallization of new matrices such as cubic $\mathrm{Gd}_{2} \mathrm{O}_{3}$. The first laser results for this new crystal $\mathrm{Yb}$ : $\mathrm{Gd}_{2} \mathrm{O}_{3}$ show interesting alternative spectral properties compared to its isotypes. Nevertheless, the laser performance up to now was lower than the ones obtained with $\mathrm{Yb}: \mathrm{Y}_{2} \mathrm{O}_{3}$. New crystals will be produced taking into account these results and also to explore new $\mathrm{Yb}$-doped isotypes such as $\mathrm{Lu}_{2} \mathrm{O}_{3}$. These first results open a very promising way for the development of flux method grown highly doped sesquioxide crystals for thindisk applications.

The authors would like to thank the "pôle de compétitivité" photonics in Aquitaine "Route des Lasers" and the French "Agence Nationale de la Recherche" (decision no ANR 2010 JCJC 0909 01) for supporting this work.

\section{References}

1. K. Petermann, G. Huber, L. Fornasiero, S. Koch, E. Mix, V. Peters, and S. A. Basun, J. Lumin. 87-89, 973 (2000).

2. L. Laversenne, Y. Guyot, C. Goutaudier, M.-Th Cohen-Adad, and G. Boulon, Opt. Mater. 16, 475 (2001).

3. L. Fornasiero, E. Mix, V. Peters, K. Petermann, and G. Huber, Ceram. Int. 26, 589 (2000).

4. A. Yoshikawa and V. Chani, Mater. Res. Soc. Bull. 34, 266 (2009).

5. J. Kong, D. Y. Tang, C. C. Chan, J. Lu, K. Ueda, H. Yagi, and T. Yanagitani, Opt. Lett. 32, 247 (2007).

6. R. Peters, C. Kränkel, K. Petermann, and G. Huber, Opt. Express 15, 7075 (2007).

7. B. Weichelt, K. Wentsch, A. Voss, M. Abdou Ahmed, and Th. Graf, Laser Phys. Lett. 9, 110 (2012).

8. M. Tokurakawa, A. Shirakawa, K. Ueda, H. Yagi, T. Yanagitani, A. A. Kaminskii, K. Beil, C. Kränkel, and G. Huber, Opt. Express 20, 10847 (2012).

9. C. R. E. Baer, C. Kränkel, C. J. Saraceno, O. H. Heckl, M. Golling, R. Peters, K. Petermann, T. Südmeyer, G. Huber, and U. Keller, Opt. Lett. 35, 2302 (2010).

10. M. Tokurakawa, A. Shirakawa, K. Ueda, H. Yagi, M. Noriyuki, T. Yanagitani, and A. A. Kaminskii, Opt. Express 17, 3353 (2009).

11. C. McMillen, D. Thomson, T. Tritt, and J. Kolis, Cryst. Growth Des. 11, 4386 (2011).

12. A. Fukabori, V. Chani, K. Kamada, F. Moretti, and A. Yoshikawa, Cryst. Growth Des. 11, 2404 (2011). 
13. A. Fukabori, V. Chani, K. Kamada, and A. Yoshikawa, J. Cryst. Growth 352, 124 (2012).

14. Ph. Veber, M. Velázquez, V. Jubera, S. Pechev, and O. Viraphong, CrystEngComm 13, 5220 (2011).

15. M. Foex and J.-P. Traverse, Rev. Int. Hautes Temp. Réfract. 3, 429 (1966).

16. O. Knacke, O. Kubaschewski, and K. Hesselmann, eds., Thermochemical Properties of Inorganic Substances, 2nd ed., Vol. 1 and 2 (Springer-Verlag, 1991).
17. V. Swamy, H. J. Seifert, and F. Aldinger, J. Alloys Compd. 269, 201 (1998).

18. W. Bo, M. Zinkevich, W. Chong, and F. Aldinger, Rare Met. 25, 549 (2006)

19. J. B. Ainscough, D. A. Moore, and S. C. Osborn, J. Nucl. Mater. 55, 229 (1975).

20. A. Pirri, G. Toci, and M. Vannini, Opt. Lett. 36, 4284 (2011). 21. J. Kong, D. Y. Tang, J. Lu, K. Ueda, H. Yagi, and T. Yanagitani, Opt. Lett. 29, 1212 (2004). 